\title{
Expression of Central Glucocorticoid Receptors after Peripheral Nerve Injury Contributes to Neuropathic Pain Behaviors in Rats
}

\author{
Shuxing Wang, Grewo Lim, Qing Zeng, Backil Sung, Yulan Ai, Gongshe Guo, Liling Yang, and Jianren Mao \\ Pain Research Group, Massachusetts General Hospital Pain Center, Department of Anesthesia and Critical Care, Massachusetts General Hospital, Harvard \\ Medical School, Boston, Massachusetts 02114
}

\begin{abstract}
Peripheral glucocorticoid receptors (GRs) play a significant role in the anti-inflammatory effects of glucocorticoids; however, the role of central GRs in nociceptive behaviors after peripheral nerve injury (neuropathic pain behaviors) remains unknown. Here we show that the development of neuropathic pain behaviors (thermal hyperalgesia and mechanical allodynia) induced by chronic constriction nerve injury (CCI) in rats was attenuated by either the GR antagonist RU38486 ( $4=2>1=0.5 \mu \mathrm{g})$ or a GR antisense oligonucleotide administered intrathecally twice daily for postoperative days $1-6$. The development of thermal hyperalgesia and mechanical allodynia after CCI also was prevented in adrenalectomized rats, whereas the GR agonist dexamethasone (100 $\mu \mathrm{g} / \mathrm{kg})$ given subcutaneously twice daily for postoperative day 1-6 restored CCI-induced neuropathic pain behaviors in the adrenalectomized rats. Mechanistically, CCI induced a time-dependent and region-specific expression of neuronal GRs primarily within the spinal cord dorsal horn ipsilateral to nerve injury, which showed a time course parallel to that of the development of neuropathic pain behaviors. Moreover, the expression of neuronal GR after CCI was mediated in part through an elevated spinal level of interleukin-6(IL-6) and protein kinase $\mathrm{C} \gamma(\mathrm{PKC} \gamma)$, because intrathecal treatment with an IL-6 antiserum, a PKC inhibitor (cheryrithrine), or PKC $\gamma$ knock-out substantially reduced the expression of neuronal GRs as well as neuropathic pain behaviors after CCI. These findings indicate a central role of neuronal GRs in the mechanisms of neuropathic pain behaviors in rats and suggest a potential role for GR antagonists in clinical management of neuropathic pain.
\end{abstract}

Key words: glucocorticoid; spinal; neuropathic pain; NMDA receptor; interleukins; protein kinase C

\section{Introduction}

Pain after injury to the nervous system (neuropathic pain) is a major chronic pain condition that remains difficult to treat. Both peripheral and central mechanisms of neuropathic pain have been proposed (Wall et al. 1974; Devor, 1983, Dougherty and Willis, 1991; Dubner, 1991; Yamamoto and Yaksh, 1992; Mao et al., 1995; Woolf and Mannion, 1999). Peripheral glucocorticoid receptors (GRs) play a significant role in the anti-inflammatory effects of glucocorticoids, which are mediated mainly through interactions between GRs and intracellular elements such as activating protein-1 at the site of tissue inflammation (Neeck et al., 2002); however, GRs have also been located in spinal cord dorsal horn neurons (De Nicola et al., 1989; Cintra et al., 1993). Activation of neuronal GRs contributes to central changes related to neuronal injury (Cameron and Dutia, 1999) and the process of learning and memory (Quirarte et al., 1997; Oitzl et al., 1998; Roosendaal et al., 1999, 2003). Of interest is that neuronal degeneration induced by activation of the NMDA receptors

Received May 24, 2004; revised Aug. 17, 2004; accepted Aug. 17, 2004.

This work was supported by United States Public Health Service R01 Grants NS 42661, NS 45681, and DA08835. Correspondence should be addressed to Dr. Jianren Mao, Pain Research Group, Massachusetts General Hospital Pain Center, Wang Ambulatory Care Center 324, Massachusetts General Hospital, Harvard Medical School, 15 Parkman Street, Boston, MA 02114. E-mail: jma0@partners.org.

D01:10.1523/JNEUROSCI.3058-04.2004

Copyright $\odot 2004$ Society for Neuroscience $\quad 0270-6474 / 04 / 248595-11 \$ 15.00 / 0$
(NMDARs) in the rat magnocellular nucleus basalis was enhanced in the presence of GR agonists (Abraham et al., 2000), and conversely, hippocampal neuronal apoptosis resulting from a glucocorticoid challenge was mediated through NMDARs and metabotropic glutamate receptors ( $\mathrm{Lu}$ et al., 2003), suggesting a functional interaction between neuronal GRs and NMDARs. Indeed, the GR level increases in the hippocampus after a focal brain injury (McCullers et al., 2002) and in the spinal cord after traumatic injury (Yan et al., 1999). Moreover, glucocorticoids could have neurotoxic effects contributing to neuronal damage (Fuxe et al., 1996). To date, a central role of GRs in the mechanisms of neuropathic pain has not been examined.

Proinflammatory cytokines including interleukin (IL)- $1 \beta$, IL-6, IL-10, and tumor necrosis factor- $\alpha$ are produced at both peripheral and central loci in response to peripheral nerve injury (Deleo et al., 1996; Arruda et al., 1998; Murphy et al., 1999; Okamoto et al., 2001; Raghavendra et al., 2002; Schafers et al., 2003). These cytokines play a significant role in inflammatory responses in part through intracellular mediators such as protein kinase $\mathrm{C}$ (PKC) and cAMP (Barkhudaryan and Dunn, 1999). Moreover, cytokines have been suggested to play a role in the development of neuropathic pain (Opree and Kress, 2000; Sweitzer et al., 2001; Milligan et al., 2003; Schafers et al., 2003; Watkins and Maier, 2003), and interleukins have been shown to enhance conditioned fear memory in part through the effects of glucocorticoids (Song 
et al., 2003). Thus, it is possible that cytokines and intracellular PKC may induce changes in neuronal GRs in response to peripheral nerve injury.

In a rat model of neuropathic pain induced by chronic constriction nerve injury (CCI) (Bennett and Xie, 1988), we examined the hypothesis that central GR would contribute to the mechanisms of neuropathic pain behaviors after peripheral nerve injury, in part through the expression of neuronal GRs mediated by proinflammatory interleukins and intracellular PKC.

\section{Materials and Methods}

Animal models of peripheral nerve injury. Adult male Sprague Dawley rats weighing 275-325 gm (Charles River Laboratories, Wilmington, MA) were used. The animal room was artificially lighted from 7:00 A.M. until 7:00 P.M. The experimental protocol was approved by our Institutional Animal Care and Use Committee. CCI rats were produced by loosely ligating a common sciatic nerve according to the method of Bennett and Xie (1988). Another rat model of peripheral never injury in which the L5 spinal nerve root on one side was tightly ligated according to the method of Kim and Chung (1992) was used in some experiments to confirm the findings in CCI rats. Sham rats were made following the same surgical procedure except for nerve ligation. Adrenalectomized rats (250-275 $\mathrm{gm})$ were purchased from Charles River Laboratories. Adrenalectomized rats were given ad libitum access to food and $0.9 \% \mathrm{NaCl}$ solution instead of water and used for the experiments at $7 \mathrm{~d}$ after the adrenal surgery that removed bilateral adrenal glands, including the medullary component. PKC $\gamma$ knock-out (KO) mice and the matched wild-type (WT) mice were purchased from Jackson Laboratory (Bar Harbor, ME).

Intrathecal catheterization and drug delivery. An intrathecal catheter was implanted in a rat under the same surgical conditions, and a PE10 catheter was inserted onto the level of the lumbar enlargement $(\sim 8.5 \mathrm{~cm}$ from the incision site for this rat age group) according to the method described previously (Yaksh and Rudy, 1976; Mao et al., 2002). Those rats exhibiting postoperative neurological deficits (e.g., paralysis) or poor grooming were excluded from the experiments as described previously (Mao et al., 2002). The following drugs were purchased from Sigma (St. Louis, MO): RU38486, spironolactone, cheryrithrine, dexamethasone, and IL-6. RU38486, cheryrithrine, dexamethasone, or spironolactone was dissolved in 10\% ethanol solution. IL-6 was dissolved in normal saline. IL-6 antiserum was purchased from R \& D Systems (Minneapolis, $\mathrm{MN}$ ) and dissolved in PBS. All drugs were injected intrathecally in a $10 \mu \mathrm{l}$ volume followed by a $10 \mu \mathrm{l}$ saline flush.

For those experiments using GR oligonucleotides, antisense sequences overlapping the respective initiation codon were designed for targeting GR mRNA: GR antisense (TGG AGT CCA TT GCA AAT), GR sense (ATT TGC CAA TGG ACT CCA), and the mixed base (TGA AGT TCA GTG TCA ACT). Sequencing was performed by MWG-Biotech (High Point, NC). Oligonucleotides were dissolved in $0.9 \%$ saline and injected ( $5 \mu \mathrm{M}$, i.t.) twice a day. After each experiment, tissue samples were harvested to examine neurochemical changes.

Behavioral tests and statistical analysis. Animals were habituated to the test environment daily (a 60 min session) for $2 \mathrm{~d}$ before baseline testing. The testing procedure for thermal hyperalgesia was performed according to a previously published method (Hargreaves et al., 1988). Temperature was set to have the baseline latency at $\sim 10-12 \mathrm{sec}$ and a cutoff of $20 \mathrm{sec}$. Mechanical allodynia was examined by applying a von Frey filament to the plantar surface of each hindpaw (Tal and Bennett, 1994). The cutoff force was $20 \mathrm{gm}$. All testing was conducted between 9:00 A.M. and 1 P.M. Data from both thermal hyperalgesia (withdrawal latency in seconds) and mechanical allodynia (threshold bending force in grams) tests were analyzed by using repeated measure two-way ANOVA across testing time points to detect overall differences among treatment groups. Whenever applicable, the data were also examined by using repeated measure twoway ANOVA across treatment groups to examine overall differences among testing time points. In both cases, when significant main effects were observed, the post hoc Newman-Keuls tests were performed to determine sources of differences. Differences were considered to be statistically significant at the level of $\alpha=0.05$.
ELISA. Plasma samples were taken between 10:00 A.M. and noon to minimize the variation of the plasma cortisol level. The cortisol ELISA kit (catalog \#RE 520 61) was purchased from IBL Immuno-Biological Laboratories (Minneapolis, MN). The standard curve was generated using the reference standard set supplied in the kit. The samples were measured according to the instructions accompanying the kit. Hydrocortisone (Sigma) was used as control, and different levels were included in every assay. The results were read using a microplate reader (Bio-TeK Instruments Winooski, VT) at wavelengths of 450 and $620 \mathrm{~nm}$. The plasma cortisol concentration was calculated based on the standard curve and presented in nanograms per milliliter.

Immunocytochemical staining. Rats were anesthetized with pentobarbital and transcardially perfused with $200 \mathrm{ml}$ of normal saline followed by $200-300 \mathrm{ml}$ of $4 \%$ paraformaldehyde in $0.1 \mathrm{M}$ phosphate buffer (PB). The lumbar spinal cords were dissected, postfixed for $1.5 \mathrm{hr}$, and kept overnight in $30 \%$ sucrose in $0.1 \mathrm{M} \mathrm{PB}$. Tissues from both experimental and control groups were then mounted together in OCT compound and frozen on dry ice. The spinal cords $(20 \mu \mathrm{m}$ sections) were cut on a cryostat, mounted serially onto microscope slides, and stored at $-80^{\circ} \mathrm{C}$. Immunocytochemical staining was used to detect GRs (1:1000, rabbit polyclonal; Santa Cruz Biotechnology, Santa Cruz, CA), neuronalspecific nuclear protein (NeuN) (1:500, mouse monoclonal; Chemicon, Temecula, CA), PKC $\gamma$ (1:500, mouse monoclonal; Santa Cruz Biotechnology), and IL-6 (1:200, goat polyclonal; R \& D Systems). Lumbar spinal cord sections were blocked with $1 \%$ goat serum in $0.3 \%$ Triton for $1 \mathrm{hr}$ at room temperature and incubated overnight at $4^{\circ} \mathrm{C}$ with a primary antibody. For controls, a primary antibody was omitted and antigen absorption (for GRs) was used in control sections. The sections were then incubated for $1 \mathrm{hr}$ at room temperature with a corresponding FITC- or Cy3conjugated secondary antibody (1:300; Chemicon). For double staining, a second primary antibody was added after the incubation with the first primary antibody for the same procedure as described above. Four to six nonadjacent spinal sections were randomly selected, analyzed using a fluorescence microscope (Olympus), recorded using a digital camera, and processed using Adobe Photoshop.

Western blot. Rats were decapitated rapidly ( $<1 \mathrm{~min}$ ) under anesthesia, and the lumbar spinal cord segments and corresponding dorsal root ganglia (DRG) were removed. The spinal segments were separated into the ipsilateral and contralateral side as well as the dorsal and ventral part and homogenized in SDS sample buffer containing a mixture of proteinase inhibitors (Sigma). The lumbar segments were harvested because CCI has the major impact at these spinal segments, and the intrathecal drug delivery also was aimed at this site. Protein samples were separated on SDS-PAGE gel (4-15\% gradient gel; Bio-Rad, Hercules, CA) and transferred to polyvinylidene difluoride filters (Millipore, Bedford, MA). The filters were blocked with $3 \%$ milk and incubated overnight at $4^{\circ} \mathrm{C}$ with a primary antibody [GR: rabbit polyclonal, 1:1000; PKA: 1:1000, rabbit polyclonal (both from Santa Cruz Biotechnology); PKC $\gamma$ : mouse monoclonal, 1:400 (Zymed Lab, San Francisco, CA); IL-6: goat polyclonal, 1:1000 (R \& D Systems); IL-10: goat polyclonal, 1:1000 (Santa Cruz Biotechnology) and $1 \mathrm{hr}$ at room temperature with HRPconjugated secondary antibody (1:700; Amersham Biosciences, Arlington Heights, IL).

The blots were visualized in ECL solution (NEN, Boston, MA) for 1 min and exposed onto hyperfilms (Amersham Biosciences) for 1-10 $\mathrm{min}$. The blots were then incubated in a stripping buffer $(67.5 \mathrm{~mm}$ Tris, $\mathrm{pH} 6.8,2 \% \mathrm{SDS}$, and $0.7 \% \beta$-mercaptoethanol) for $30 \mathrm{~min}$ at $50^{\circ} \mathrm{C}$ and reprobed with a polyclonal rabbit anti- $\beta$-actin antibody (1:20,000; Alpha Diagnostic International, San Antonio, TX) or in some cases with both $\beta$-actin and extracellular signal-related kinase 2 (ERK2) (1:2000, rabbit polyclonal; Cell Signaling Technology, Beverly, MA) as loading controls. The Western analysis was made in triplicates. The density of specific bands was measured with a computer-assisted imaging analysis system and normalized against loading controls. Differences were compared using repeated measure one-way ANOVA followed by post hoc Newman-Keuls tests.

$R T-P C R$. Total RNA was isolated from the lumbar spinal cord segments, divided into the dorsal and ventral horn and ipsilateral and contralateral side, by using TRIZOL Reagent (TEL-TEST, Friendswood, 
TX). After incubation for $15 \mathrm{~min}$ at $4^{\circ} \mathrm{C}$, chloroform was added for the phase separation. The upper aqueous phase was collected, and RNA was precipitated through mixing the sample with isopropyl alcohol. The RNA pellet was washed once with $75 \%$ ethanol and air-dried, which was finally redissolved in RNase-free water. A260/A280 ratios were between 1.6 and 1.8.
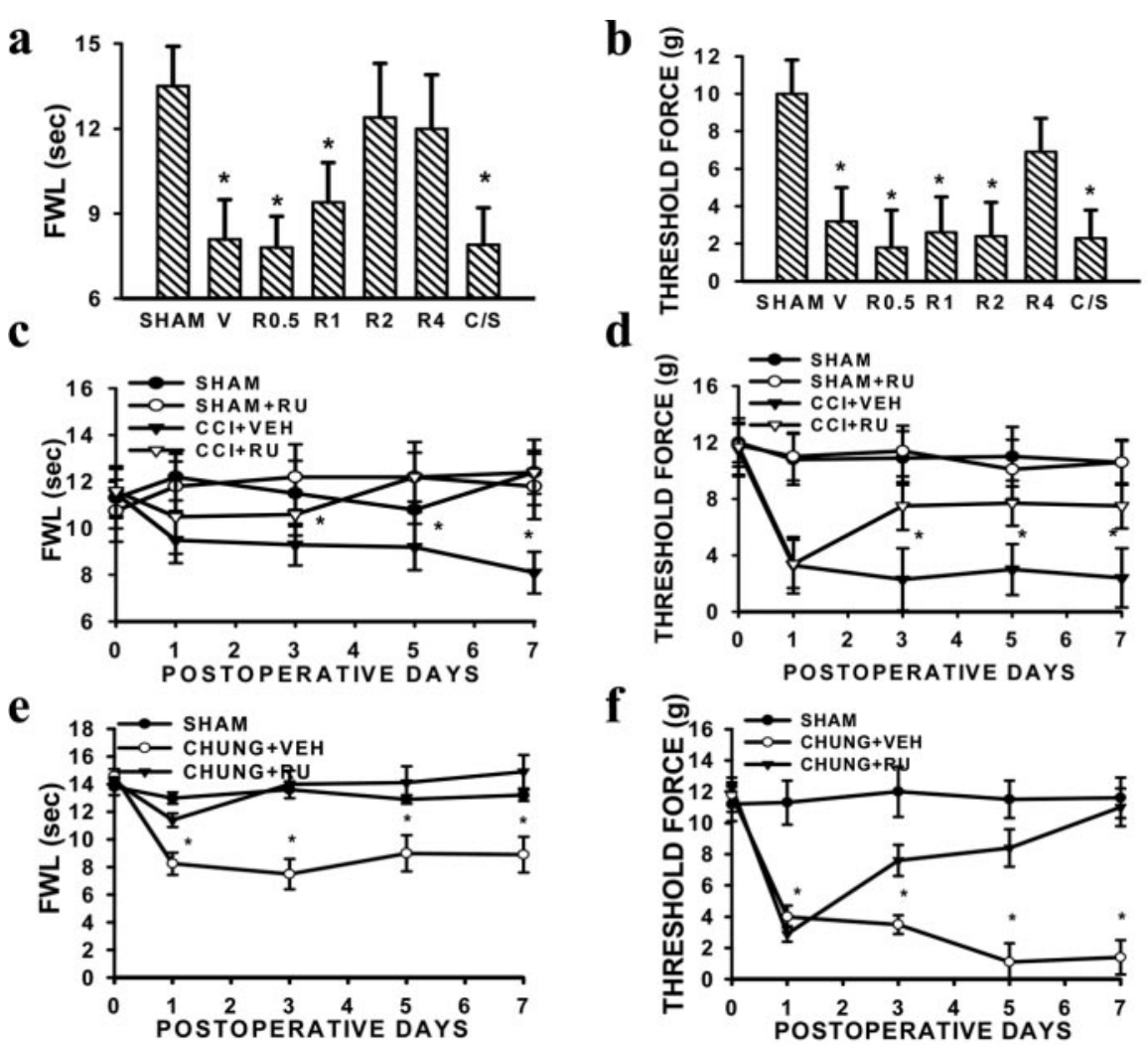

g
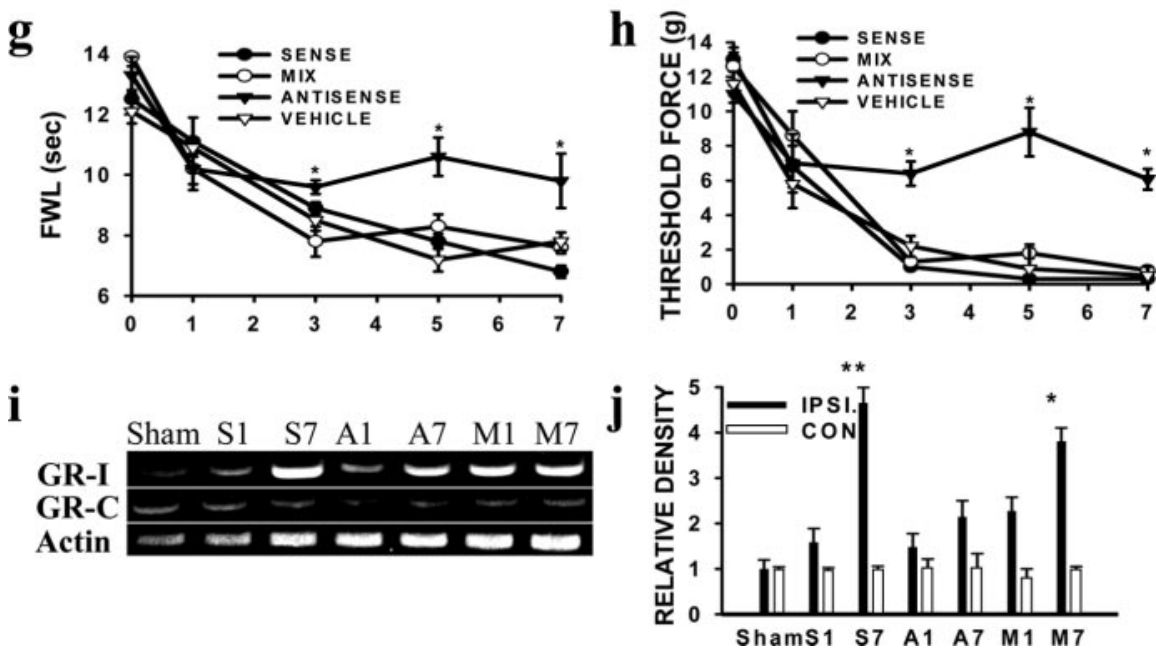

Figure 1. $a, b$, The dose-response effects of RU38486 on thermal hyperalgesia ( $a$ ) and mechanical allodynia $(b)$ examined on postoperative day 7 in $C(\mathrm{Cl}$ rats. The mineralocorticoid receptor antagonist spironolactone $[3 \mu \mathrm{g} ; \mathrm{CC} 1$ plus spironolactone (C/S)] did not affect hyperalgesia and allodynia in $\mathrm{CCl}$ rats. $\mathrm{V}, \mathrm{CCl}+$ vehicle; $\mathrm{R} 0.5$ to $\mathrm{R} 4$, $\mathrm{Cl}$ rats treated with $0.5-4 \mu \mathrm{g} \mathrm{RU} 38486$. $c-f$, The development of thermal hyperalgesia $(c, e)$ and mechanical allodynia $(d, f)$ in $C(\mathrm{C}$ rats $(c, d)$ or Chung rats $(e, f)$ was diminished by the GR antagonist RU38486 (2 $\mu$; $\mathrm{CCl}+\mathrm{RU}$ or CHUNG + RU), but not vehicle (CCI+VEH or CHUNG + VEH), given twice daily for the first 6 postoperative days. RU38486 alone did not affect the behavioral responses in sham rats $(c, d, \operatorname{sham}+\mathrm{RU})$. In $a-f$, ${ }^{*} p<$ 0.05 compared with sham rats. $g$, $h$, The development of thermal hyperalgesia $(g)$ and mechanical allodynia $(h)$ in $C(\mathrm{Cl}$ rats was diminished in $\mathrm{CCl}$ rats treated with the GR antisense OND ( $5 \mu \mathrm{M}$, i.t.) twice daily for 6 consecutive postoperative days. ${ }^{*} p<0.05$ compared with each of the rest of the groups. $i, j$, , The GR expression (RT-PCR) was substantially attenuated in $C(\mathrm{Cl}$ rats treated with the GR antisense OND. ${ }^{*} p<0.05$ and ${ }^{* *} p<0.01$ compared with day 1 of each corresponding group. S1, S7, A1, A7, and M1, M7, Day 1 and day 7 from $C(\mathrm{Cl}$ rats treated with the GR sense (S), antisense (A), and a mixed base (M), respectively. In all figures, refer to the main text for the number of animals per group.
RT-PCR was performed using the Titan One Tube RT-PCR System (Roche, Indianapolis, IN). Each PCR amplification with a volume of 25 $\mu l$ contained $100 \mathrm{ng}$ of total RNA, $0.4 \mu \mathrm{m}$ each primer, $0.2 \mathrm{~mm}$ each deoxynucleotide, $5 \mathrm{~mm}$ dithiothreitol, $5 \mathrm{U}$ RNase inhibitor, $1.5 \mathrm{~mm}$ $\mathrm{MgCl}_{2}$, and $0.5 \mu \mathrm{l}$ of enzyme mix. The reactions were performed in an $\mathrm{MJ}$ research thermocycler using individual programs as follows: GR: forward primer (AAA TCT TTG TTG GGC TCA GGC TTC CTT GT), reverse primer (GAA GAG AAA CGA GCA AGC ATA G), program $\left(95^{\circ} \mathrm{C}\right.$ for $30 \mathrm{sec}$, $43^{\circ} \mathrm{C}$ for $1 \mathrm{~min}, 72^{\circ} \mathrm{C}$ for $1 \mathrm{~min}$ ); mineralocorticoid receptor (MR): forward primer (TAT CTG CAC TGT CGC TCT ATT ACT CTA CC), reverse primer (AAA TCT TTG TTG GGC TCA GGC TTC CTT GT), program $\left(95^{\circ} \mathrm{C}\right.$ for $30 \mathrm{sec}, 50^{\circ} \mathrm{C}$ for $1 \mathrm{~min}, 72^{\circ} \mathrm{C}$ for $\left.1 \mathrm{~min}\right)$; IL-6: forward primer (CGA AAG TCA ACT CCA TCT GCC), reverse primer (GGC AAC TGG CGT GAA GTC TCT), program $\left(95^{\circ} \mathrm{C}\right.$ for 1 $\min , 55^{\circ} \mathrm{C}$ for $1 \mathrm{~min}, 72^{\circ} \mathrm{C}$ for $\left.1 \mathrm{~min}\right)$; $\mathrm{PKC} \gamma$ : forward primer (GCT CCC ACA TCA GAT GAG ATC CA), reverse primer (CGT CCT GGG CTG GCA CCG AAG AA), program $\left(95^{\circ} \mathrm{C}\right.$ for $1 \mathrm{~min}, 55^{\circ} \mathrm{C}$ for $2 \mathrm{~min}, 72^{\circ} \mathrm{C}$ for 3 min); PKC $\alpha$ : forward primer (ACC CTC AGT GGA ATG AGT CCT TCA CGT), reverse primer (TTA GAT GGC TGC TTC CTG TCT TCT GAA), program $\left(95^{\circ} \mathrm{C}\right.$ for $1 \mathrm{~min}, 55^{\circ} \mathrm{C}$ for $2 \mathrm{~min}, 72^{\circ} \mathrm{C}$ for $3 \mathrm{~min}$ ). There were $32-35$ cycles in all reactions except for $\mathrm{PKC} \alpha$, in which 40 cycles were used to improve the yield. Each program ended with $7 \mathrm{~min}$ at $68^{\circ} \mathrm{C}$ and stored at $4^{\circ} \mathrm{C}$. Every PCR was accompanied by one negative control reaction without template RNA. PCR products were analyzed by gel electrophoresis on an ethidium bromide-stained 1\% agarose gel (Sigma) in Tris-borate-EDTA buffer. The amount of RNA per RT-PCR sample was normalized using PCR with primers specific for $\beta$-actin: forward primer (TAC AAC CTC CTT GCA CC), reverse primer (ACA ATG CCG TGT TCA ATG G), program $\left(95^{\circ} \mathrm{C}\right.$ for $1 \mathrm{~min}, 55^{\circ} \mathrm{C}$ for $1 \mathrm{~min}, 72^{\circ} \mathrm{C}$ for $1 \mathrm{~min}$ ). Each band was then measured with a computerassisted imaging analysis system and normalized against the loading control. Differences were compared using a one-way ANOVA followed by post hoc Newman-Keuls tests.

\section{Results}

Role of central GRs in neuropathic pain behaviors

The results from a series of behavioral experiments, using the GR antagonist RU38486, the GR agonist dexamethasone, GR oligonucleotides (ONDs), or adrenalectomy (ADL), collectively indicate that central GRs contributed to the development of neuropathic pain behaviors after peripheral nerve injury.

\section{Effect of the GR antagonist RU38486}

The effects of the GR antagonist RU38486 on neuropathic pain behaviors were examined in eight groups of rats including (1) CCI plus vehicle, (2-5) CCI plus $0.5,1$, 2 , and $4 \mu \mathrm{g}$ of RU38486, (6) CCI plus the 
MR antagonist spironolactone ( $3 \mu \mathrm{g}$ ) [ the selected spironolactone dose was used to block MR in a previous study examining the role of MR in morphine-induced locomotion (Marinelli et al., 1998)], (7) sham plus RU38486, and (8) sham plus vehicle. Each agent was given twice daily (intrathecally) for 6 postoperative days beginning immediately after operation. RU38486, but not spironolactone, dose-dependently $(4=2>1=0.5 \mu \mathrm{g})$ reduced thermal hyperalgesia and mechanical allodynia as compared with vehicle-treated CCI rats (Fig. $1 a-d)(p<0.05 ; n=6-9)$. RU38486 alone did not change thermal or mechanical nociceptive threshold in shamoperated rats (Fig. $1 c, d)(p>0.05 ; n=5)$. Repeated treatment with RU38486 (2 $\mu \mathrm{g}$, i.t.) using the same regimen for CCI rats also attenuated the development of thermal hyperalgesia and mechanical allodynia in the Chung model (Fig. 1e,f) $(p<$ $0.05 ; n=6$ ), suggesting a broad effect of RU38486 on neuropathic pain behaviors after peripheral nerve injury.

Effect of GR antisense ONDs

Although there are reports on mice with genetically altered GRs, the mice are either lethal or unavailable to us (Tronche et al., 1999; Gartner et al., 2002; St. Hilaire et al., 2003). As an alternative, an antisense OND against GRs was delivered to the lumbar spinal segments via an intrathecal catheter. In this set of experiments, CCI rats each received a GR antisense OND (5 $\mu \mathrm{M})$, sense OND, mixed base OND, or a vehicle. Each treatment was given twice daily for the first 6 postoperative days, and the spinal cord samples were harvested. The development of thermal hyperalgesia and mechanical allodynia was significantly attenuated in those CCI rats treated with the GR antisense as compared with the remaining groups (Fig. $1 g, h)(p<$ $0.05 ; n=5-7)$. The same antisense OND treatment did not affect the baseline nociceptive responses in sham rats $(p>0.05$; $n=5$ ). The effects of the GR antisense OND on neuropathic pain behaviors were associated with a substantial reduction of the GR expression (RT-PCR) in CCI rats treated with the GR antisense OND as compared with other OND treatment groups (Fig. 1 $i, j$ ) $(p<0.05 ; n=5-7)$.

Effect of $A D L$

The development of neuropathic pain behaviors after CCI was also examined in ADL rats lacking the ability to produce corticoids (Smith et al. 1991; Castonguay et al., 2002). The baseline plasma cortisol level was barely detectable by ELISA in ADL rats, and CCI did not result in an increase in the plasma cortisol level in ADL rats (Fig. $2 a)(p>0.05 ; n=6)$. In contrast, there was a time-dependent change in the plasma cortisol level in CCI rats without ADL (Fig. $2 a)(p<0.05 ; n=6)$. In non-ADL rats, the plasma cortisol level was dramatically increased $1 \mathrm{~d}$ after opera- a

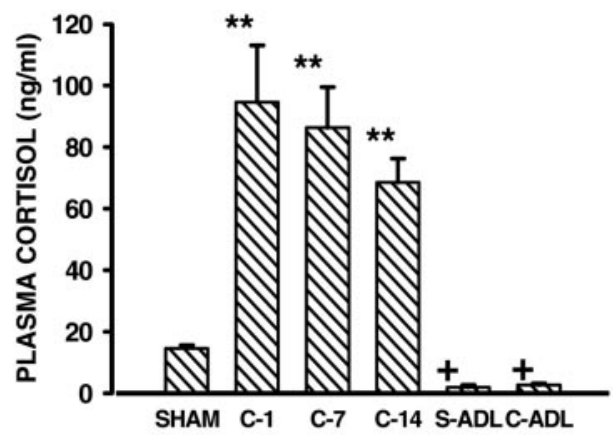

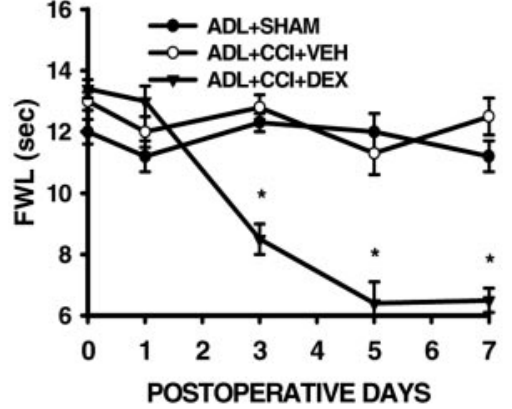

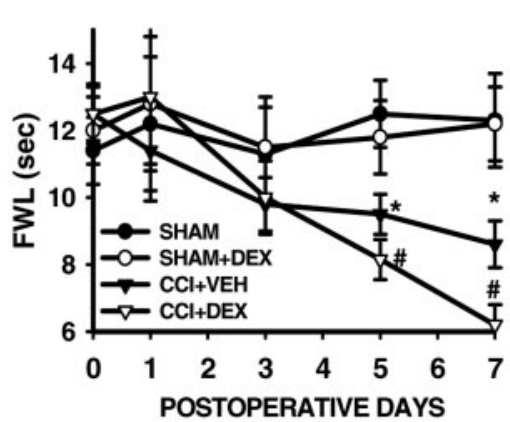

c

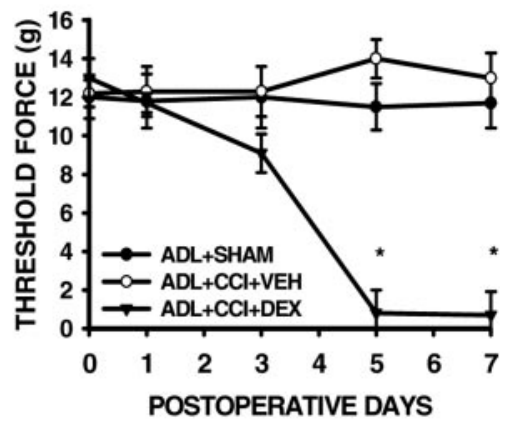

e

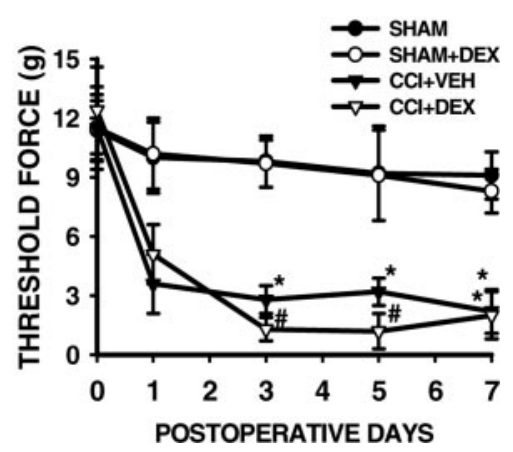

Figure 2. a, Changes in the plasma cortisol level after CCI. C-1 to C-14, Day 1 to day 14 after CCl; S-ADL and C-ADL, sham and CCI rats with adrenalectomy, respectively. ${ }^{* *} p<0.01$ compared with sham rats. ${ }^{+} p<0.05$ compared with both sham and $C \mathrm{Cl}$ rats. $b, c, A D L$ rats failed to develop thermal hyperalgesia $(b)$ or mechanical allodynia $(c)$ after $C \mathrm{CI}(\mathrm{ADL}+\mathrm{CCI}+\mathrm{VEH})$ compared with dexamethasone (ADL + CCl+DEX) for postoperative days 1-6.d, e, Dexamethasone (DEX; $4 \mu \mathrm{g})$ given intrathecally twice daily for the first 6 postoperative days exacerbated the development of thermal hyperalgesia $(d)$ and mechanical allodynia $(e)$ in $C($ rats. Dexamethasone alone did not affect the behavioral responses in sham rats (SHAM+DEX). ${ }^{*} p<0.05$ compared with sham rats. ${ }^{p} p<0.05$ compared with both sham and $C \mathrm{Cl}+\mathrm{VEH}$ groups.

tion, reflecting an acute stress response, and remained elevated up to at least $14 \mathrm{~d}$ after CCI as compared with sham operation (Fig. $2 a)(p<0.05 ; n=6)$. ADL did not change baseline thermal or mechanical nociceptive threshold, nor did it change grooming and survival as compared with non-ADL rats.

After CCI, ADL rats failed to develop neuropathic pain behaviors as compared with sham operation (Fig. $2 b, c)(p>0.05 ; n=5-6)$, whereas non-ADL rats developed significant neuropathic pain behaviors during the same period (Fig. 1c,d). The development of neuropathic pain behaviors after CCI was restored in ADL rats, however, when treated with dexamethasone $(100 \mu \mathrm{g} / \mathrm{kg}$, s.c.) twice daily for postoperative days $1-6$ (Fig. $2 b, c)(p<0.05 ; n=7)$, whereas the same dexamethasone treatment did not affect the baseline nociceptive responses. A similar dexamethasone regimen has been shown to restore the glucocorticoid effect on the insulin-mediated muscle protein synthesis in ADL rats (Long et al., 2003). 
a
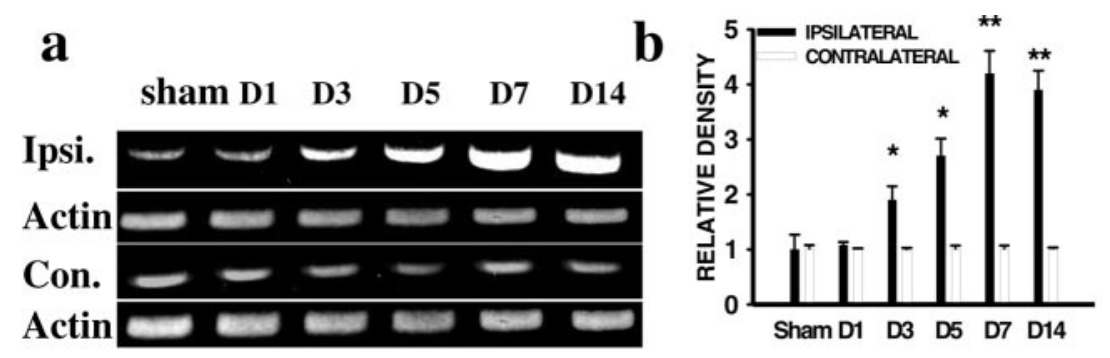

c

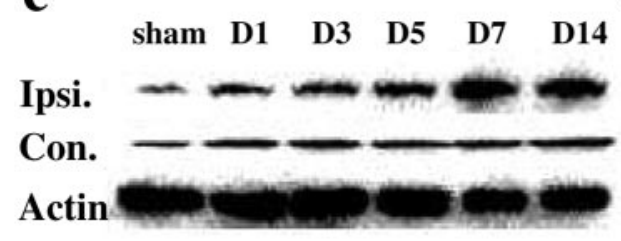

e

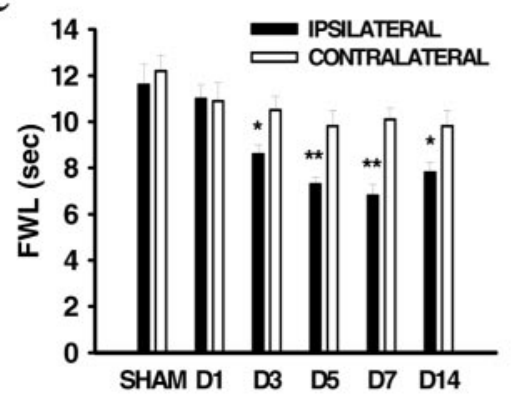

g

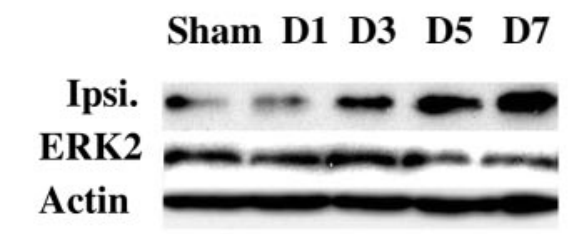

i

Vent. Horn Thalamus Sham CCI Sham CCI

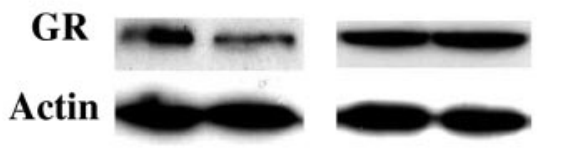

d
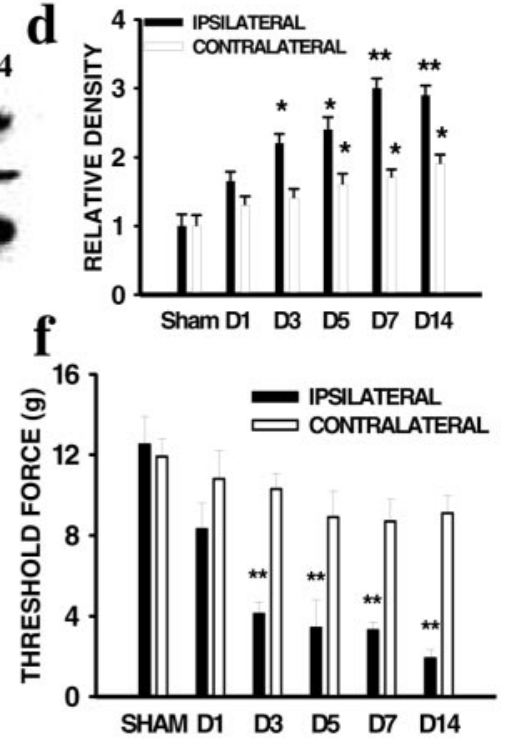

h

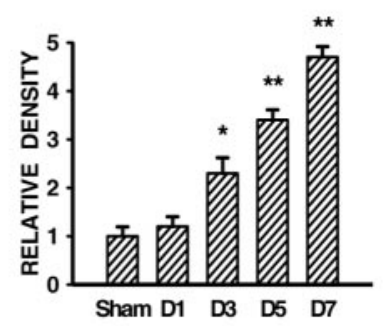

j

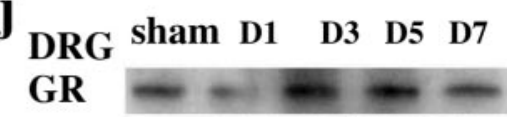

ERK2

\section{Actin}

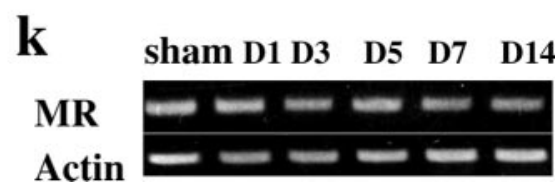

Figure 3. $a, c$, Time course of the GR expression ( $a, \mathrm{RT}-\mathrm{PCR} ; c$, Western blot, $95 \mathrm{kDa}$ ) within the spinal cord dorsal horn ipsilateral (Ipsi.) and contralateral (Con.) to CCl or sham operation (sham). Actin ( $\beta$-actin, $42 \mathrm{kDa}$ ) is a loading control.b, d, Statistical analysis of the GR expression. Relative density, Relative density of RT-PCR and Western blot bands calculated by normalizing each band with its corresponding loading control band. $e, f$, Time course of the development of thermal hyperalgesia $(e)$ and mechanical allodynia ( $f$ ) after C(I. FWL, Foot-withdrawal latency. $g$, $h$, Time course of the GR expression (Western blot) and statistical analysis within the spinal cord dorsal horn ipsilateral to $L 5$ nerve root ligation (the Chung model). Both $\beta$-actin and ERK2 are loading controls. In all panels, D1-D14, postoperative day 1 to day $14 ;{ }^{*} p<0.05$ and ${ }^{* *} p<0.01$ compared with sham rats on the same side of the spinal cord dorsal horn. $i-k$, The GR expression was not significantly changed after $C(\mathrm{Cl}$ in the ipsilateral spinal cord ventral horn $(i)$, contralateral thalamus $(i)$, or lumbar DRG $(j)$ when examined on day 7 after $C(\mathrm{Cl}$, nor was there a significant change in MR expression within the ipsilateral spinal cord dorsal horn after CCI ( $k$, RT-PCR).

Effect of the GR agonist dexamethasone

To examine whether dexamethasone would exacerbate the development of neuropathic pain behaviors in non-ADL rats, the synthetic GR agonist dexamethasone ( 2 or $4 \mu \mathrm{g}$ ) or a vehicle was administered intrathecally twice daily for the first 6 postoperative days to both CCI and sham rats. CCI rats treated with dexamethasone developed significant thermal hyperalgesia and mechanical allodynia that followed a time course similar to that of CCI rats treated with a vehicle, indicating that dexamethasone did not shorten the onset of neuropathic pain behaviors. Both thermal hyperalgesia and mechanical allodynia were exacerbated, however, in CCI rats treated with $4 \mu \mathrm{g}$ (not $2 \mu \mathrm{g}$ ) of dexamethasone (Fig. $2 d, e)(p<0.05 ; n=$ 5-6). Dexamethasone $(4 \mu \mathrm{g})$ alone did not affect thermal and mechanical nociceptive threshold in sham rats (Fig. $2 d, e$ ) $(p>0.05 ; n=5-6)$.

Expression of neuronal GRs after CCI

To explore the possible mechanisms of GR-mediated neuropathic pain behaviors in CCI rats, we first examined whether CCI would alter the expression of central GRs. CCI but not sham operation produced a time-dependent GR expression within the spinal cord dorsal horn ipsilateral to the site of nerve injury as revealed by both RT-PCR and Western blot (Fig. $3 a-d)(n=4-6)$. The significant increase in both GR mRNA and protein level was detected on postoperative day 3 in CCI rats and lasted at least up to postoperative day 14 (Fig. 3a-d) ( $p<0.05)$. Although there was a moderate increase in the GR expression (Western blot) on the contralateral spinal cord dorsal horn in CCI rats as compared with sham operation, the GR expression was significantly greater on the side ipsilateral rather than contralateral to CCI (Fig. 3b,d) $(p<0.05)$. For controls, a set of samples from sham rats was taken on days $1,3,5$, and $7(n=3-4)$. In addition, spinal cord samples were also taken from a group of naive rats $(n=4)$. Because there were no differences in the spinal GR expression (RT-PCR and Western blot) in sham rats across these time points as compared with the naive rats $(p>0.05)$ and the GR expression reached a stable level in CCI rats on postoperative day 7 (Fig. 3a-d), the data from day 7 after sham operation were presented (Fig. $3 a-d$ ).

The time course of GR changes was parallel to that of the development of thermal hyperalgesia and mechanical allodynia in CCI rats shown both in previous studies (Bennett and Xie, 1988; Mao et al., 
1992a; Yamamoto and Yaksh, 1992) and in the present study (Fig. 3e,f) $(n=5-6)$. A similar pattern of GR expression within the ipsilateral spinal cord dorsal horn was confirmed in the Chung model induced by ligating the L5 lumbar spinal nerve root (Fig. $3 g, h$ ). In contrast, there were no significant changes in the GR expression from the ipsilateral lumbar DRG, the spinal cord ventral horn, and the contralateral thalamus (Fig. 3i,j), nor was there a change in the MR level within the ipsilateral spinal cord dorsal horn after CCI (Fig. 3k).

The topographic distribution of GR immunoreactivity (GR-ir) also indicated a predominant increase in GR-ir within the spinal cord dorsal horn ipsilateral to CCI. GR-ir was increased primarily within superficial laminas (I-II), as compared with deeper laminas (III-VI), of the ipsilateral spinal cord dorsal horn (Fig. 4A,B). The majority of GR-expressing cell profiles expressed NeuN-ir (a neuronal marker), indicating a major association of GRs with neuronal cells (Fig. 4C-E). Of interest is that a number of GR-expressing cell profiles expressed PKC $\gamma$-ir, and almost all $\mathrm{PKC} \gamma$-expressing cell profiles within laminas I-II also showed GR-ir (Fig. $4 F-H$ ). Thus, the data from RT-PCR, Western blot, and immunohistochemistry indicate that peripheral nerve injury induced a time-dependent and region-specific increase in neuronal GR expression within the spinal cord dorsal horn.

\section{Role of IL-6 in GR expression}

Several interleukins are proinflammatory cytokines that contribute to inflammatory responses after tissue injury (Barkhudaryan and Dunn, 1999). Our immunohistochemical data showed an increased level of IL-6-ir within the superficial laminas of the ipsilateral spinal cord dorsal horn in CCI rats (Fig. $4 I, J$ ), the same spinal locus with an increased GR expression after CCI. This initial finding, along with the data indicating IL6-induced GR upregulation in human osteoblast-like cell lines (Dovio et al., 2001), led us to examine whether IL-6 served as a mediator between peripheral nerve injury and the expression of neuronal GR. Indeed, CCI induced an increase in IL-6 (RT-PCR and Western blot) with a time course similar to that of the GR expression (Fig. $5 a-d$ ), whereas the change in IL-10 was minimal as compared with IL-6 after CCI (Fig. $5 e)(n=5)$. Changes in IL-6 mRNA from spinal cord dorsal horn samples indicate a de novo production of IL- 6 in the CNS in response to peripheral nerve injury.

To further examine the relationship between IL- 6 and the GR expression, an IL-6 antiserum ( $5 \mu \mathrm{g}$ ) or control serum was given intrathecally once a day for postoperative days 1-6 beginning immediately after the operation. The IL-6 antiserum dose was chosen based on the literature (Milligan et al., 2003; Schafers et al., 2003) and our pilot experiment. IL-6 antiserum, but not con-
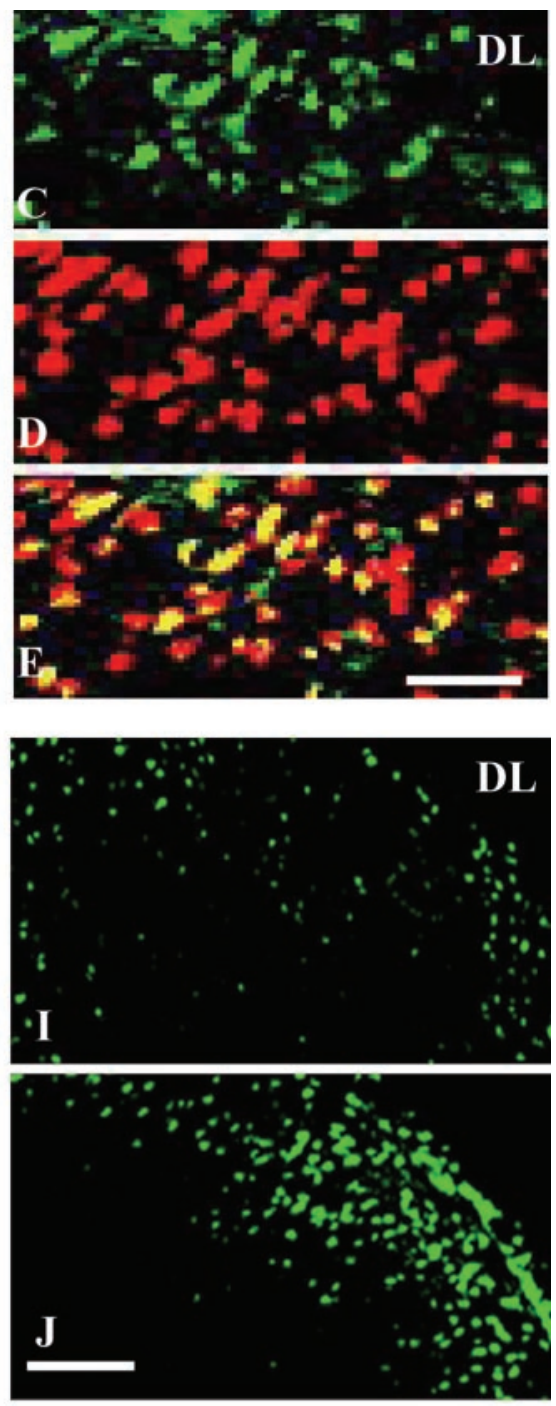

Figure 4. $a, b$, Topographic distribution of GR in a spinal cord section ( $a$ ) taken from a representative $\mathrm{CCl}$ rat on postoperative day 7, showing differences in the GR expression within the spinal cord dorsal horn ipsilateral (ipsi.) and contralateral to CCI. $b$, on postoperative day 7 . Scale bars: $a, b, 120 \mu \mathrm{m} ; i, j, 100 \mu \mathrm{m} ; c-e, 60 \mu \mathrm{m} ; f-h, 40 \mu \mathrm{m}$. DL, Dorsolateral part of the spinal cord dorsal horn indicating the orientation of spinal sections shown in $c-e, f-h, i, j$.

trol serum, significantly attenuated the GR expression (Fig. $5 f$ ) $(p<0.05 ; n=5-6)$ and neuropathic pain behaviors (Fig. $5 g, h$ ) $(p<0.05 ; n=5-6)$ in CCI rats when examined on postoperative day 7 .

In addition, exogenous IL-6 itself (33 $\mu$ g, i.t.) given once daily for $6 \mathrm{~d}$ to naive rats without nerve injury induced a significant increase in the GR expression (RT-PCR and Western blot) within the spinal cord dorsal horn as compared with vehicle-treated naive controls (Fig. $6 a, b)(p<0.05 ; n=4-5)$. The IL-6-induced GR expression returned to the baseline level at $7 \mathrm{~d}$ after the discontinuation of the IL- 6 treatment in these naive rats (Fig. $6 b$ ) $(p>0.05)$. The IL- 6 treatment that induced the GR expression also resulted in thermal hyperalgesia and mechanical allodynia in these naive rats, when examined on day 7 after the IL- 6 treatment for $6 \mathrm{~d}$. Both thermal hyperalgesia and mechanical allodynia were attenuated at $30 \mathrm{~min}$ after the intrathecal administration of the GR antagonist RU38486 (2 $\mu$ g) (Fig. $6 c, d)(p<0.05 ; n=5-8)$. 
$\mathbf{a}$

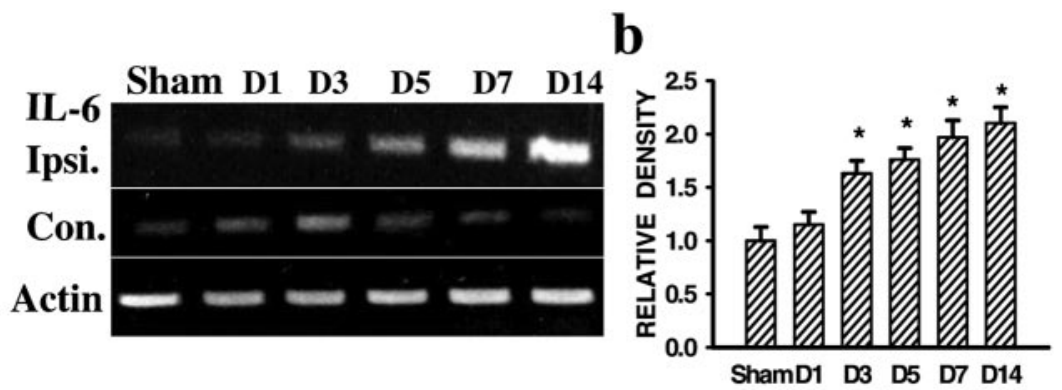

c

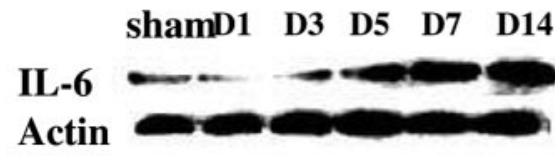

e
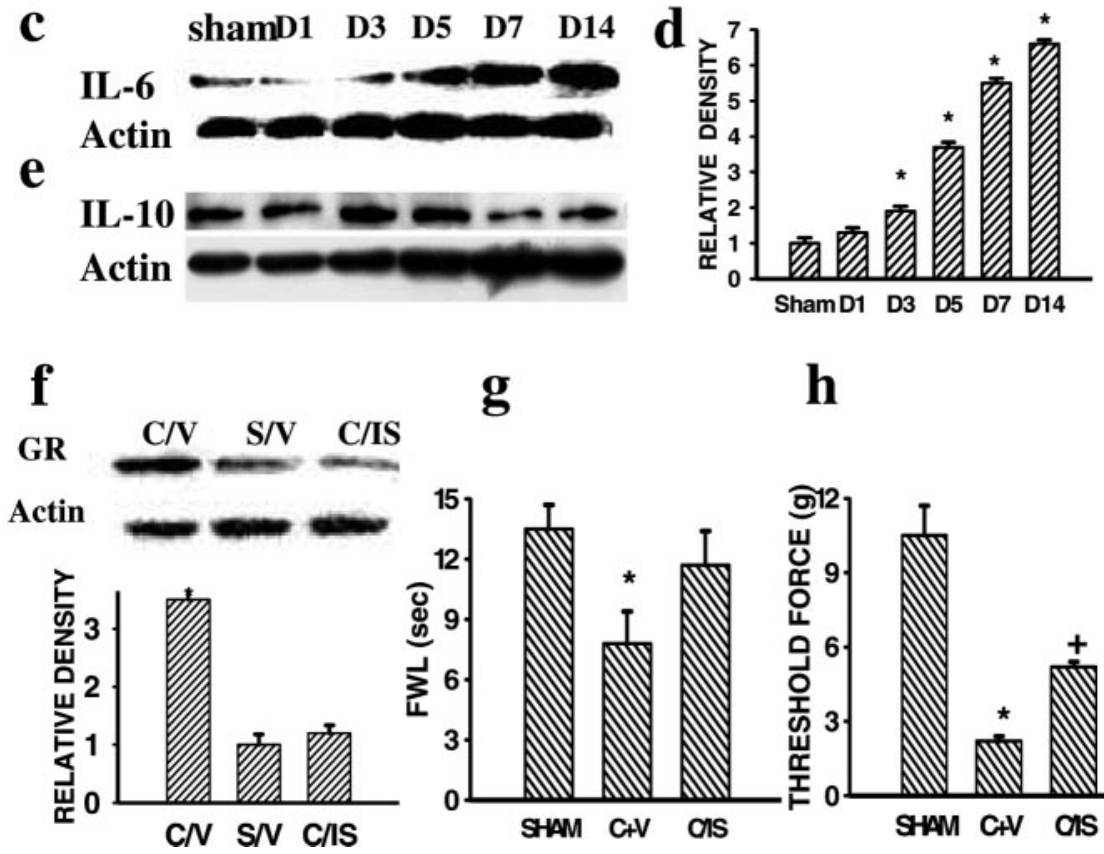

g

h
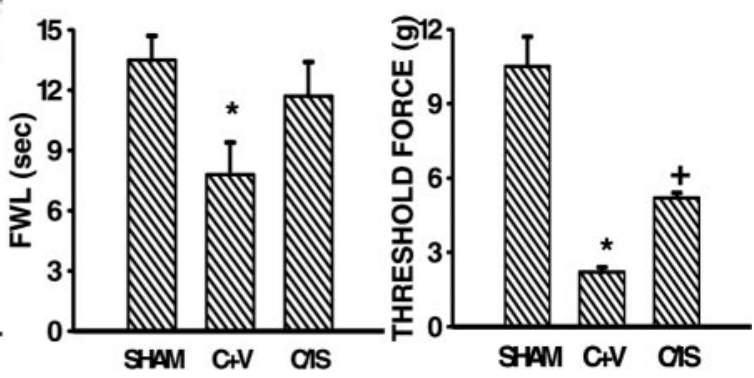

Figure 5. $a, b, \mathrm{RT}-\mathrm{PCR}(a)$, Western blot (c) $(27 \mathrm{kDa})$, and statistical analysis $(b, d)$ showing the time course of changes in IL-6 within the spinal cord dorsal horn of sham and CCl rats. ${ }^{*} p<0.05$ compared with sham rats (ipsilateral side only).e, There were no significant changes in IL-10 within the ipsilateral spinal cord dorsal horn after CCl. $f$, IL- 6 antiserum (5 $\mu$ g, i.t.) given once daily for the first 6 postoperative days attenuated the GR expression within the ipsilateral spinal cord dorsal horn of CCI rats. C/V, CCI plus control serum; S/V, sham plus control serum; C/IS, CCI plus IL- 6 antiserum. ${ }^{*} p<0.05$ compared with CCI rats treated with IL-6 antiserum. $g, h$, IL-6 antiserum (5 $\mu$ g, i.t.) given once daily for the first 6 postoperative days attenuated the development of thermal hyperalgesia $(g)$ and mechanical allodynia $(h)$ in $C C$ rats when examined on day $7 . C+V$, CCI plus control serum; SHAM, sham plus control serum; C/IS, CCI plus IL- 6 antiserum. ${ }^{*} p<0.05$ compared with sham rats. ${ }^{+} p<0.05$ compared with both sham rats and $\mathrm{CCl}$ rats treated with control serum.

RU38486 alone did not affect the baseline withdrawal latencies to thermal or mechanical stimulation $(p>0.05)(n=4)$. Together with the results from IL- 6 antiserum in CCI rats, the data indicate that IL- 6 contributed to the GR expression after CCI.

\section{Role of PKC $\boldsymbol{\gamma}$ in GR expression}

Previous studies have suggested that PKC and cAMP/PKA may be potential intracellular mediators of the IL-6 effects (Barkhudaryan and Dunn, 1999). Thus, we asked whether PKC or PKA could mediate GR expression by first examining changes of both PKC (PKC $\gamma$ and PKC $\alpha$ ) and PKA after CCI. CCI induced a significant upregulation of $\operatorname{PKC} \gamma$, but not $\operatorname{PKC} \alpha$, within the spinal cord dorsal horn with a time course similar to that of the GR expression (Fig. $7 a-d)(p<0.05 ; n=5)$. In contrast, there was no significant change in the PKA expression after CCI as compared with sham operation (Fig. $7 d)(p>0.05 ; n=5)$. These findings are consistent with a known role of $\mathrm{PKC} \gamma$ in neuropathic pain behaviors (Mao et al., 1995; Malmberg et al., 1997).

If PKC $\gamma$ played a role in the IL-6-induced GR expression after
CCI, IL-6 antiserum should prevent the upregulation of both GRs and PKC $\gamma$ in CCI rats. In those CCI rats treated with IL-6 antiserum ( $5 \mu$ g, i.t.) given once a day for postoperative days $1-6$, the PKC $\gamma$ upregulation was significantly reduced when examined on day 7 as compared with those given a control serum (Fig. 7e) $(p<$ $0.05 ; n=5)$. Conversely, exogenous IL-6 itself (33 $\mu$ g, i.t.) given once daily for $6 \mathrm{~d}$ to naive rats without nerve injury induced a significant increase in $\mathrm{PKC} \gamma$ within the spinal cord dorsal horn as compared with vehicle-treated naive controls (Fig. $7 f, g$ ) $(p<0.05 ; n=4-5)$. The PKC $\gamma$ expression induced by IL- 6 returned to the baseline in these naive rats at $7 \mathrm{~d}$ after the discontinuation of the IL- 6 treatment (Fig. $7 g)(p>0.05 ; n=4)$.

Moreover, the GR expression was significantly attenuated in those CCI rats treated with the selective PKC inhibitor cheryrithrine $(10 \mu \mathrm{g}$, i.t.), but not a vehicle or a low dose cheryrithrine $(2.5 \mu \mathrm{g})$, given twice a day for 6 postoperative days (Fig. $8 a)(p<0.05 ; n=5)$. Cheryrithrine (10 $\mu$ g, i.t.) also effectively attenuated the GR expression in naive rats treated with IL-6 (33 $\mu$ g, i.t.) given once daily for $6 \mathrm{~d}$ as compared with the IL-6 alone group (Fig. $8 a)(p<0.05 ; n=4-5)$, whereas cheryrithrine $(10 \mu \mathrm{g})$ alone did not affect the GR expression in sham rats (Fig. $8 a)(p>$ $0.05, n=4)$.

The involvement of PKC $\gamma$ in the GR expression after CCI was further indicated from the experiment using PKC $\gamma \mathrm{KO}$ and matched WT mice. Although the GR expression was upregulated in the WT mice $7 \mathrm{~d}$ after CCI, this CCI-induced GR expression was nearly abolished in $\mathrm{PKC} \gamma$ KO mice as compared with the WT mice (Fig. $8 b)(p<0.05 ; n=5)$. There was a lack of baseline PKC $\gamma$ expression in uninjured PKC $\gamma \mathrm{KO}$ mice as compared with uninjured PKC $\gamma$ WT mice (Fig. 8c). Neuropathic pain behavior (thermal hyperalgesia) after CCI was significantly attenuated in $\mathrm{PKC} \gamma \mathrm{KO}$ mice as compared with PKC $\gamma$ WT mice in the present experiment (Fig. 8d) $(p<0.05 ; n=5)$, a finding similar to that shown in a previous report using another peripheral nerve injury model (Malmberg et al., 1997). Collectively, the data from (1) CCI rats treated with cheryrithrine, (2) naive rats treated with IL-6 and cheryrithrine, and (3) CCI mice lacking the PKC $\gamma$ expression indicate that $\mathrm{PKC} \gamma$ is an important intracellular mediator between the effect of IL-6 and GR expression after CCI.

\section{Discussion}

The present study demonstrates that (1) peripheral nerve injury induced a time-dependent expression of neuronal GRs primarily within the ipsilateral spinal cord dorsal horn, (2) the expression of neuronal GRs was mediated, at least in part, through an elevated spinal level of IL- 6 and PKC $\gamma$, and (3) spinal neuronal GRs contributed to the development of neuropathic pain behaviors 
after CCI. These findings indicate that GRs play a central role in contributing to the cellular mechanisms of neuropathic pain behaviors in rats.

Our data suggest a possible sequence of events related to the expression of neuronal GRs in CCI rats. Peripheral nerve injury elevated cytokines such as IL-6 in the CNS, as indicated by an increased spinal level of both IL-6 mRNA and protein, leading to the expression of neuronal GRs through intracellular mediators such as PKC $\gamma$. A critical site involved in this process is the spinal cord dorsal horn ipsilateral to nerve injury, because the spinal cord ventral horn, the DRG, and the contralateral thalamus showed no significant changes in the GR expression after CCI. Several lines of evidence support a role of IL- 6 and PKC $\gamma$ in the expression of neuronal GRs. (1) Both IL-6 and PKC $\gamma$ were increased after CCI with a time course parallel to that of the GR change. (2) The expression of neuronal GRs was prevented by either blocking IL-6 with an antiserum or inhibiting $\mathrm{PKC}$ by the $\mathrm{PKC}$ inhibitor cheryrithrine; the same dose of cheryrithrine also blocked the upregulation of the spinal cannabinoid-1 receptor after CCI in our previous study (Lim et al., 2003). (3) The GR expression was substantially diminished in $\mathrm{PKC} \gamma \mathrm{KO}$ mice, and PKC $\gamma$ is known to be involved in the mechanisms of neuropathic pain behaviors in rodents (Mao et al., 1995; Malmberg et al., 1997). These findings, however, do not exclude the possibility that additional proinflammatory cytokines and intracellular signaling pathways could be activated by nerve injury (Opree and Kress, 2000; Sweitzer et al., 2001; Milligan et al., 2003) and contribute to the expression of neuronal GRs.

Neuronal GRs can be activated by circulatory corticosteroids and/or locally produced neurosteroids known to interact with GRs (Compagnone and Mellon, 2000; Plassart-Schiess and Baulieu, 2001; Vallee et al., 2001). Our data showed a significant and sustained increase in the plasma cortisol level after nerve injury, suggesting that an altered corticosteroid level could serve as an important source of endogenous GR agonists after CCI. Notably, the time course of GR expression generally parallels that of behavioral changes in CCI rats. Although there was a moderate change in the GR expression within the spinal cord dorsal horn contralateral to CCI as compared with sham operation, statistically significant behavioral changes were not observed on the contralateral hindpaw, a finding that is similar to a number of neurochemical changes observed in this and other animal models of neuropathic pain (Mao et al., 1995).

Our data demonstrate a role of GRs in the development of neuropathic pain behaviors after CCI. Collectively, the development of neuropathic pain behaviors in CCI rats was attenuated through the following: (1) intervention of those cellular elements (e.g., IL-6, PKC $\gamma$ ) mediating the expression of GRs; (2) inhibition of GRs with the GR antagonist RU38486 (RU38486 also attenuated the development of neuropathic pain behaviors in the b
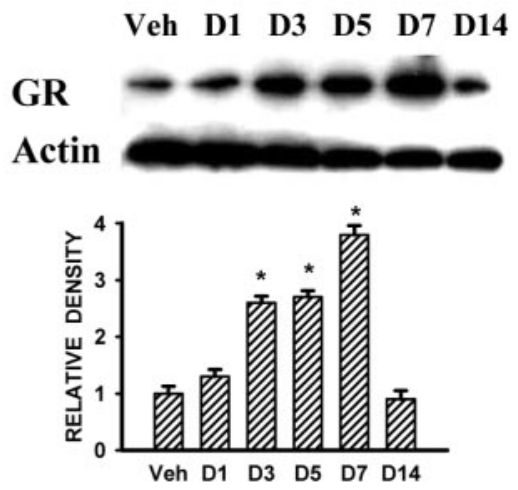

d

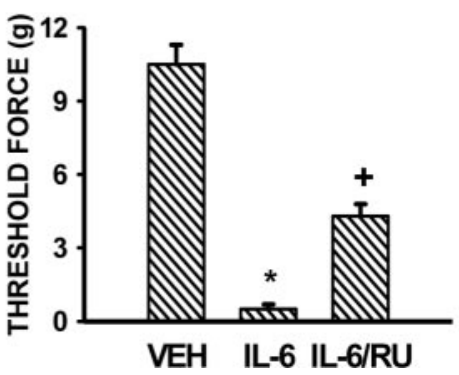

Figure 6. $a, b, \mathrm{RT}-\mathrm{PCR}(a)$ and Western blot $(b)$ and statistical analysis showing the time course of GR expression within the spinal cord dorsal horn of naive rats induced by IL-6 (33 $\mu \mathrm{g}$, i.t.) given once daily for 6 consecutive days. D1-D7, Day 1 to day 7 of the IL- 6 treatment. Note that the GR expression returned to baseline in $b$ at $7 \mathrm{~d}$ after the discontinuation of IL- 6 treatment (D14) both thermal hyperalgesia ( $c$ ) and mechanical allodynia $(d)$ induced by IL-6 $(33 \mu \mathrm{g}$, i.t.) given once daily for 6 consecutive days in naive rats. ${ }^{*} p<0.05$ compared with vehicle (VEH).

Chung model of nerve injury); (3) prevention of an increase in endogenous GR agonists after CCI in ADL rats; and (4) genetic alteration of the GR expression with a GR antisense OND. Conversely, neuropathic pain behaviors were exacerbated in CCI rats treated with the synthetic GR agonist dexamethasone, and a daily supplement with subcutaneous dexamethasone restored CCIinduced neuropathic pain behaviors in ADL rats. Several technical considerations are worth mentioning. First, although RU38486 has been used extensively as a conventional GR antagonist and is the only one available commercially, RU38486 does have other actions such as those of an antiprogesterone (Mao et al., 1992b). The antiprogesterone effect is unlikely to be contributory in CCI rats, because the experiment using GR antisense ONDs yielded results similar to those using RU38486 in exclusively male rats. Second, given that MR was not increased after $\mathrm{CCI}$ and the MR antagonist spironolactone did not change neuropathic pain behaviors, MR also is unlikely to be involved in this process. Third, intrathecal drug injection may potentially influence DRG and regions beyond the targeted spinal segments. A primary site of RU38486 action should be within the spinal cord dorsal horn in the present experiments, however, because (1) the intrathecal injection technique has been shown to be a method of regional drug delivery (Mao et al., 1992a; Yamamoto and Yaksh, $1992)$ and the agent was delivered in a small volume $(10 \mu \mathrm{l})$ through a catheter threaded to the level of lumbar spinal seg- 
a

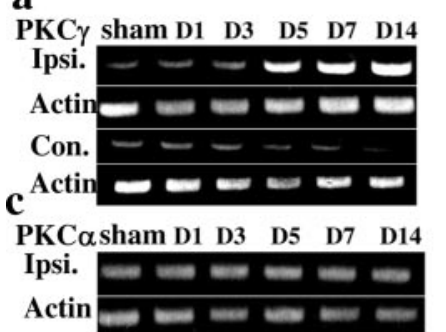

b

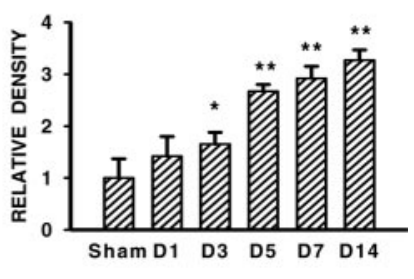

d

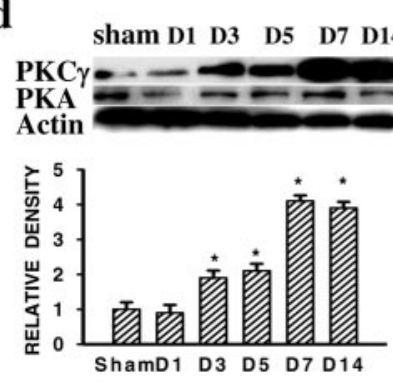

f
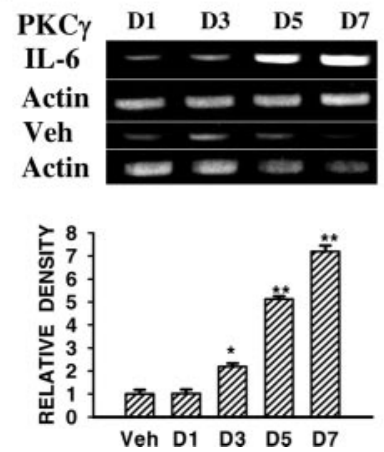

e
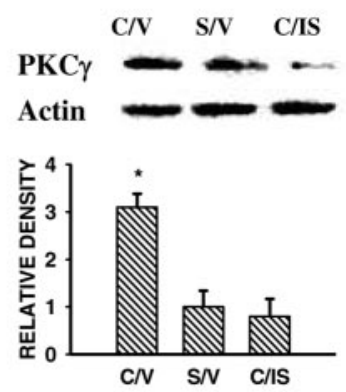

g
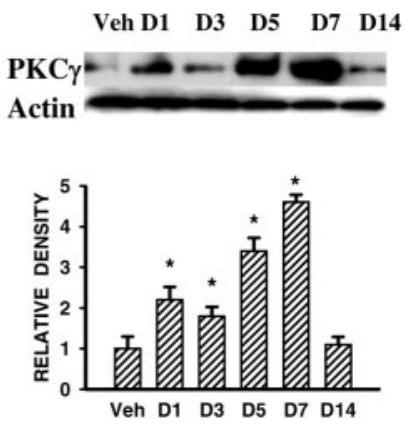

Figure 7. $a-d$, RT-PCR ( $a)$ and Western blot $(d)(80 \mathrm{kDa})$ and statistical analysis $(b, d)$ showing the time course of changes in PKC $\gamma$ within the spinal cord dorsal horn of sham and CCI rats. There was no significant change in PKC $\alpha(c)$ or PKA $(d)$ within the ipsilateral spinal cord dorsal horn after $C \mathrm{Cl} .{ }^{*} p<0.05$ and ${ }^{* *} p<0.01$ compared with sham rats (ipsilateral side only).e, IL-6 antiserum (5 $\mu$ g, i.t.) given once daily for the first 6 postoperative days attenuated the expression of PKC $\gamma$ within the ipsilateral spinal cord dorsal horn of $\mathrm{CCl}$ rats. ${ }^{*} p<0.05$ compared with $\mathrm{CCl}$ rats treated with IL- 6 antiserum. See Figure 5 for additional labels. $f, g$, RT-PCR $(f)$ and Western blot $(g)$ and statistical analysis showing the time course of PKC $\gamma$ expression within the spinal cord dorsal horn of naive rats induced by IL-6 (33 $\mu \mathrm{g})$ or vehicle (veh) given intrathecally once daily for 6 consecutive days. ${ }^{*} p<0.05$ compared with vehicle. D1-D7, Day 1 to day 7 of the IL-6 treatment. Note that the GR expression returned to baseline in $g$ at $7 \mathrm{~d}$ after the discontinuation of IL-6 treatment (D14).

ments confirmed at the tissue harvest, and (2) no GR changes were detected in the ipsilateral DRG and contralateral thalamus after CCI.

The cellular mechanisms of GR actions on the development of neuropathic pain behaviors in CCI rats remain to be elucidated. GR is a cytosolic receptor and activation of GR requires the formation of a GR-homodimer after dissociation from its cytosolic complex consisting of heat shock proteins (Drouin et al., 1992; Neeck et al., 2002). A GR-homodimer binds to nuclear-specific DNA responsive elements and regulates gene transcription and translation for a number of cellular elements (Drouin et al., 1992; Karst et al. 2002). In addition, GR action could take place through nongenomic mechanisms (Barrett and Vedeckis, 1996; Refojo et al., 2001), including (1) the GR-mediated inhibition of bradykinin-induced $\mathrm{Ca}^{2+}$ influx in PC12 cells (Qiu et al., 2003), (2) the effect of cortisol through GRs on prolactin release (Borski

a $\mathrm{S} / \mathrm{V} \mathrm{C} / \mathrm{V} \mathrm{C/CHCHIL/V} \mathrm{IL/CH}$

b PKC $\gamma$-KO PKC $\gamma$-WT

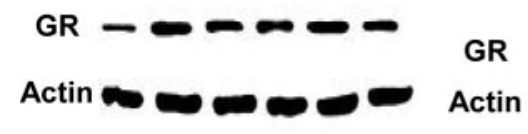

GR Con. Ipsi. Con. Ipsi.
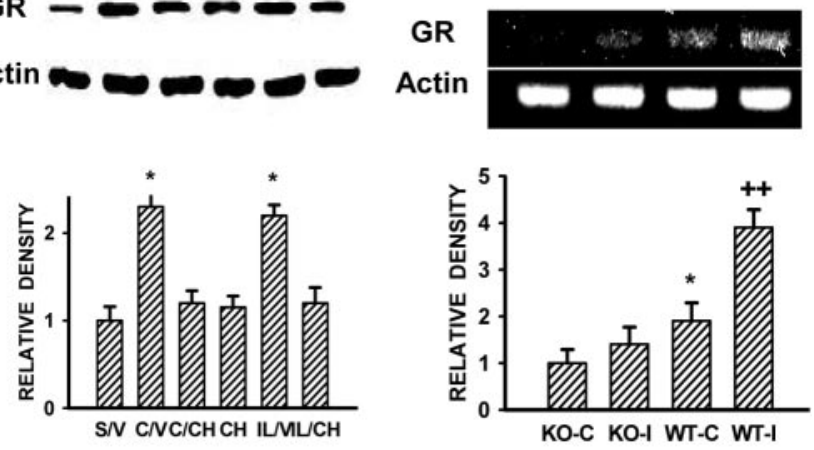

C
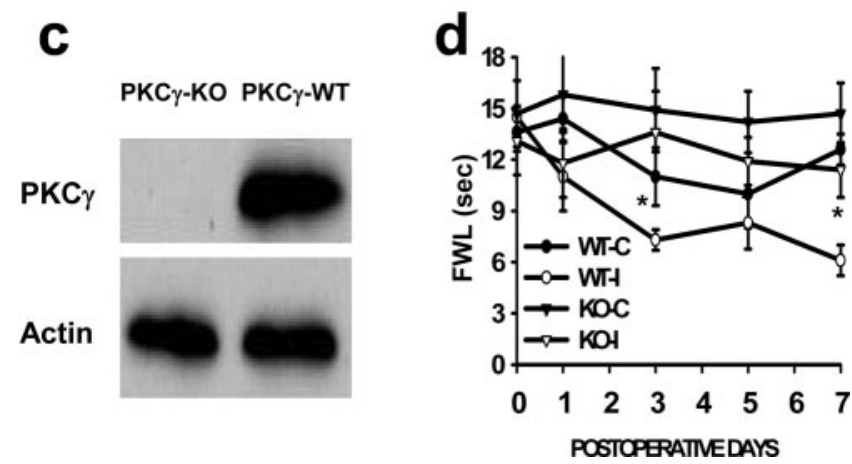

Figure 8. $a$, The PKC inhibitor cheryrithrin (10 $\mu$ g, i.t.) given twice daily for the first 6 postoperative days attenuated the GR expression within the ipsilateral spinal cord dorsal horn of $\mathrm{CCl}$ rats when examined on day 7. The same cheryrithrine treatment also attenuated the GR expression induced by the IL- 6 treatment in naive rats. $S / N$, Sham rats with vehicle; $C / V$, CCl rats with vehicle; $\mathrm{C} / \mathrm{CH}, \mathrm{CCl}$ rats with cheryrithrine; $\mathrm{CH}$, cheryrithrine alone; IL/V, naive rats with IL-6 and vehicle; $\mathrm{L} / \mathrm{CH}$, naive rats with $\mathrm{IL}-6$ and cheryrithrine. ${ }^{*} p<0.05$ compared with the corresponding vehicle or sham group. $b$, The GR expression (RT-PCR) after $C(\mathrm{Cl}$ was nearly blocked in PKC $\gamma$-KO mice compared with PKC $\gamma$-WT when examined on postoperative day $7 .{ }^{*} p<0.05$ compared with the contralateral spinal cord dorsal horn of PKC $\gamma$ KO mice (KO-C). ${ }^{++} p<0.01$ compared with PKC $\gamma$ KO mice and the contralateral spinal cord dorsal horn (WT-C) of the WT mice. C, Lack of baseline PKC $\gamma$ expression (Western blot, $80 \mathrm{kDa}$ ) within the spinal cord dorsal horn in uninjured PKC $\gamma$-KO mice compared with uninjured PKC $\gamma$-WT mice. $d$, The development of thermal hyperalgesia was reduced in PKC $\gamma$-KO mice compared with PKC $\gamma$-WT mice. ${ }^{*} p<$ 0.05 compared with PKC $\gamma$-WT mice. FWL, Foot-withdrawal latency.

et al., 2002), (3) regulation by GRs of glutamate binding in the injured spinal cord (Gonzalez et al., 1995), and (4) a corticosterone-induced acute elevation of intracellular $\mathrm{Ca}^{2+}$ concentration in hippocampal neurons (Takahashi et al., 2002). Of interest is that a number of previous studies have suggested that GRs may have modulatory effects on the expression and function of NMDAR. For example, GR activation has been shown to (1) potentiate NMDA-induced responses in dopaminesensitive neurons within the ventral tegmental area (Cho and Little, 1999) and modulate $\mathrm{Ca}^{2+}$ channel conductance (Nair et al., 1998), (2) regulate NMDAR-mediated long-term depression (Coussens et al., 1997) and elevate intracellular $\mathrm{Ca}^{2+}$ concentration in hippocampal neurons (Takahashi et al., 2002), and (3) mediate NMDA-induced neuronal degeneration in the rat magnocellular nucleus basalis (Abraham et al., 2000). Given that NMDAR plays a critical role in the mechanisms of neuropathic pain (Mao et al., 1992a, 1995; Yamamoto and Yaksh, 1992; Woolf and Mannion, 1999), it would be of considerable interest in future studies to examine the relationship between GR actions and NMDAR expression and function in relation to the development 
as well as maintenance of neuropathic pain behaviors after peripheral nerve injury.

The present findings may have important clinical implications. First, high doses of systemic corticosteroids are often used to reduce signs of regional tissue inflammation such as edema and neurogenic extravasation during the immediate phase of nerve injury (Kingery et al., 1999, 2001). Although the antiinflammatory effects of corticosteroids could be beneficial under such circumstances, our results indicate that an unexpected adverse effect of GR activation within the CNS could contribute to the neural mechanisms of neuropathic pain behaviors. Second, neuronal degeneration within the spinal cord dorsal horn occurs after peripheral nerve injury (Sugimoto et al., 1990; Mao et al., 1997; Moore et al., 2002), and recent studies have indicated detrimental effects of GR agonists on NMDA-induced neuronal degeneration (Abraham et al., 2000) and in neuronal apoptosis during autoimmune-related inflammation (Diem et al., 2003). Thus, actions of central GRs could potentially worsen neuronal degeneration induced by peripheral nerve injury. Third, endogenous corticosteroids are elevated in chronic pain patients (Moore et al., 1983), and both stress and pain-related responses can activate the hypothalamic-pituitary-adrenocortical axis (Lephart et al., 2003). In this regard, psychological disturbances and chronic stress could influence central nociceptive processing via neuronal GRs, thereby contributing to a long-known clinical connection between psychological and stress responses and pain experience (Dubrovsky, 2000). Our results also suggest potential new clinical treatment for neuropathic pain. For instance, a GR antagonist such as RU38486 could be used to protect the central effects of GR activation. A GR antagonist could also be used in combination with other compounds (e.g., an anti-inflammatory agent, a $\mathrm{PKC}$ inhibitor) to reduce chronic neuropathic pain.

\section{References}

Abraham I, Harkany T, Horvath K, Veenema AH, Penke B, Nyakas C, Luiten PG (2000) Chronic corticosterone administration dose-dependently modulates abeta(1-42)- and NMDA-induced neurodegeneration in rat magnocellular nucleus basalis. J Neuroendocrinol 12:486-494.

Arruda JL, Colburn RW, Rickman AJ, Rutkoski MD, Deleo JA (1998) Increase of interleukin-6 mRNA in the spinal cord following peripheral injury in the rat: potential role of IL- 6 in neuropathic pain. Brain Res Mol Brain Res 62:228-235.

Barkhudaryan N, Dunn AJ (1999) Molecular mechanisms of actions of interleukin- 6 on the brain, with special reference to serotonin and the hypothalamo-pituitary-adrenocortical axis. Neurochem Res 24:1169-1180.

Barrett TJ, Vedeckis WV (1996) Occupancy and composition of proteins bound to the AP-1 sites in the glucocorticoid receptor and c-jun promoters after glucocorticoid treatment and in different cell types. Recept Signal Transduct 6:179-193.

Bennett GJ, Xie YK (1988) A peripheral mononeuropathy in rat that produces disorders of pain sensation like those seen in man. Pain 33:87-107.

Borski RJ, Hyde GN, Fruchtman S (2002) Signal transduction mechanisms mediating rapid, nongenomic effects of cortisol on prolactin release. Steroids $67: 539-548$.

Cameron SA, Dutia MB (1999) Lesion-induced plasticity in rat vestibular nucleus neurons is dependent on glucocorticoid receptor activation. J Physiol (Lond) 518:151-158.

Castonguay TW, Beaulieu S, Eskay RL, Barden N, Kamara K, Khozin S, Lustberg L, Brown L (2002) The effects of adrenalectomy and aldosterone replacement in transgenic mice expressing antisense RNA to the type 2 glucocorticoid receptor. Physiol Behav 77:417-423.

Cho K, Little HJ (1999) Effects of corticosterone on excitatory amino acid responses in dopamine-sensitive neurons in the ventral tegmental area. Neuroscience 88:837-845.

Cintra A, Molander C, Fuxe K (1993) Colocalization of Fos- and glucocorticoid receptor-immunoreactivities is present only in a very restricted population of dorsal horn neurons of the rat spinal cord after nociceptive stimulation. Brain Res 632:334-338.
Compagnone NA, Mellon SH (2000) Neurosteroids: biosynthesis and functions of these novel neuromodulators. Front Neuroendocrinol 21:1-56.

Coussens CM, Kerr DS, Abraham WC (1997) Glucocorticoid receptor activation lowers the threshold for NMDA-receptor-dependent homosynaptic long-term depression in the hippocampus through activation of voltage-dependent calcium channels. J Neurophysiol 78:1-9.

Deleo JA, Colburn RW, Nichols M, Malhotra A (1996) Interleukin-6mediated hyperalgesia/allodynia and increased spinal IL-6 expression in a rat mononeuropathy model. J Interferon Cytokine Res 16:695-700.

De Nicola AF, Moses DF, Gonzalez S, Orti E (1989) Adrenocorticoid action in the spinal cord: some unique molecular properties of glucocorticoid receptors. Cell Mol Neurobiol 9:179-192.

Devor M (1983) Nerve pathophysiology and mechanisms of pain in causalgia. J Auton Nerve System 7:371-384.

Diem R, Hobom M, Maier K, Weissert R, Storch MK, Meyer R, Bahr M (2003) Methylprednisolone increases neuronal apoptosis during autoimmune CNS inflammation by inhibition of an endogenous neuroprotective pathway. J Neurosci 23:6993-7000.

Dougherty PM, Willis WD (1991) Modification of the responses of primate spinothalamic neurons to mechanical stimulation by excitatory amino acids and an $N$-methyl-D-aspartate antagonist. Brain Res 542:15-22.

Dovio A, Masera RG, Sartori ML, Racca S, Angeli A (2001) Autocrine upregulation of glucocorticoid receptors by interleukin- 6 in human osteoblast-like cells. Calcif Tissue Int 69:293-298.

Drouin J, Sun YL, Tremblay S, Lavender P, Schmidt TJ, de Lean A, Nemer M (1992) Homodimer formation is rate-limiting for high affinity DNA binding by glucocorticoid receptor. Mol Endocrinol 6:1299-1309.

Dubner R (1991) Neuronal plasticity and pain following peripheral tissue inflammation or nerve injury. In: Proceedings of 5th World Congress on Pain. Pain research and clinical management, Vol 5 (Bond M, Charlton E, Woolf CJ eds), pp 263-276. Amsterdam: Elsevier.

Dubrovsky B (2000) The specificity of stress responses to different nocuous stimuli: neurosteroids and depression. Brain Res Bull 51:443-455.

Fuxe K, Diaz R, Cintra A, Bhatnagar M, Tinner B, Gustafsson JA, Ogren SO, Agnati LF (1996) On the role of glucocorticoid receptors in brain plasticity. Cell Mol Neurobiol 16:239-258.

Gartner H, Graul MC, Oesterreicher TJ, Finegold MJ, Henning SJ (2002) Development of the fetal intestine in mice lacking the glucocorticoid receptor (GR). J Cell Physiol 194:80-87.

Gonzalez S, Coirini H, Gonzalez Deniselle MC, Gonzalez S, Calandra R, De Nicola AF (1995) Time-dependent effects of dexamethasone on glutamate binding, ornithine decarboxylase activity and polyamine levels in the transected spinal cord. J Steroid Biochem Mol Biol 55:85-92.

Hargreaves K, Dubner R, Brown F, Flores C, Joris J (1988) A new and sensitive method for measuring thermal nociception in cutaneous hyperalgesia. Pain 32:77-88.

Karst H, Nair S, Velzing E, Rumpff-van Essen L, Slagter E, Shinnick-Gallagher P, Joels M (2002) Glucocorticoids alter calcium conductances and calcium channel subunit expression in basolateral amygdale neurons. Eur J Neurosci 16:1083-1089.

Kim SH, Chung JM (1992) An experimental model of peripheral neuropathy produced by segmental spinal nerve ligation in the rat. Pain 50:355-363.

Kingery WS, Castellote JM, Maze M (1999) Methylprednisolone prevents the development of autotomy and neuropathic edema in rats, but has no effect on nociceptive thresholds. Pain 80:555-566.

Kingery WS, Guo T, Agashe GS, Davies MF, Clark DJ, Maze M (2001) Glucocorticoid inhibition of neuropathic limb edema and cutaneous neurogenic extravasation. Brain Res 913:140-148.

Lephart ED, Galindo E, Bu LH (2003) Stress (hypothalamic-pituitaryadrenal axis) and pain response in male rats exposed lifelong to high vs. low phytoestrogen diets. Neurosci Lett 342:65-68.

Lim G, Sung B, Ji RR, Mao J (2003) Upregulation of spinal cannabinoid-1receptors following peripheral nerve injury enhances the effects of Win $55,212-2$ on neuropathic pain behaviors in rats. Pain 105:275-283.

Long W, Barrett EJ, Wei L, Liu Z (2003) Adrenalectomy enhances the insulin sensitivity of muscle protein synthesis. Am J Physiol Endocrinol Metab 284:E102-E109.

Lu J, Goula D, Sousa N, Almeida OF (2003) Ionotropic and metabotropic glutamate receptor mediation of glucocorticoid-induced apoptosis in hippocampal cells and the neuroprotective role of synaptic $N$-methyl-Daspartate receptors. Neuroscience 121:123-131. 
Malmberg AB, Chen C, Tonegawa S, Basbaum AI (1997) Preserved acute pain and reduced neuropathic pain in mice lacking PKC gamma. Science 278:279-283.

Mao J, Price DD, Mayer DJ, Lu J, Hayes RL (1992a) Intrathecal MK-801 and local nerve anesthesia synergistically reduce nociceptive behaviors in rats with experimental peripheral mononeuropathy. Brain Res 576:254-262.

Mao J, Regelson W, Kalimi M (1992b) Molecular mechanisms of RU 486 action: a review. Mol Cell Biol 109:1-8.

Mao J, Price DD, Mayer DJ (1995) Mechanisms of hyperalgesia and opiate tolerance: a current view of their possible interactions. Pain 62:259-274.

Mao J, Price DD, Zhu J, Lu J, Mayer DJ (1997) The inhibition of nitric oxide-activated poly(ADP-ribose) synthetase attenuates trans-synaptic alteration of spinal cord dorsal horn neurons and neuropathic pain in the rat. Pain 72:355-366.

Mao J, Sung B, Ji RR, Lim G (2002) Chronic morphine induces downregulation of spinal glutamate transporters: implications in morphine tolerance and abnormal pain sensitivity. J Neurosci 22:8312-8323.

Marinelli M, Aouizerate B, Barrot M, Le Moal M, Piazza PV (1998) Dopamine-dependent responses to morphine depend on glucocorticoid receptors. Proc Natl Acad Sci USA 95:7742-7747.

McCullers DL, Sullivan PG, Scheff SW, Herman JP (2002) Traumatic brain injury regulates adrenocorticosteroid receptor mRNA levels in rat hippocampus. Brain Res 947:41-49.

Milligan ED, Twining C, Chacur M, Biedenkapp J, O’Connor K, Poole S, Tracey K, Martin D, Maier S, Watkins LR (2003) Spinal glia and proinflammatory cytokine mediate mirror-image neuropathic pain in rats. J Neurosci 23:1026-1040.

Moore KA, Kohno T, Karchewski LA, Scholz J, Baba H, Woolf CJ (2002) Partial peripheral nerve injury promotes a selective loss of GABAergic inhibition in the superficial dorsal horn of the spinal cord. J Neurosci 22:6724-6731.

Moore RA, Evans PJ, Smith RF, Lloyd JW (1983) Increased cortisol excretion in chronic pain. Anesthesia 38:788-791.

Murphy PG, Ramer MS, Borthwick L, Gauldie J, Richardson PM, Bisby MA (1999) Endogenous interleukin-6 contributes to hypersensitivity to cutaneous stimuli and changes in neuropeptides associated with chronic nerve constriction in mice. Eur J Neurosci 11:2243-2253.

Nair SM, Werkman TR, Craig J, Finnell R, Joels M, Eberwine JH (1998) Corticosterone regulation of ion channel conductances and mRNA levels in individual hippocampal CA1 neurons. J Neurosci 18:2685-2696.

Neeck G, Renkawitz R, Eggert M (2002) Molecular aspects of glucocorticoid hormone action in rheumatoid arthritis. Cytokines Cell Mol Ther 7:61-69.

Oitzl MS, Fluttert M, Sutanto W, de Kloet ER (1998) Continuous blockade of brain glucocorticoid receptors facilitate spatial learning and memory in rats. Eur J Neurosci 10:3759-3766.

Okamoto K, Martin DP, Schmelzer JD, Mitsui Y, Low PA (2001) Pro- and anti-inflammatory cytokines gene expression in rat sciatic nerve chronic constriction injury model of neuropathic pain. Exp Neurol 169:386-391.

Opree A, Kress M (2000) Involvement of the proinflammatory cytokines tumor necrosis factor-alpha, IL-1beta, and IL- 6 but not IL- 8 in the development of heat hyperalgesia: effects on heat-evoked calcitonin generelated peptide release from rat skin. J Neurosci 20:6289-6293.

Plassart-Schiess E, Baulieu E (2001) Neurosteroids: recent findings. Brain Res Brain Res Rev 37:133-140.

Qiu J, Wang CG, Haung XY, Chen YZ (2003) Nongenomic mechanism of glucocorticoid inhibition of bradykinin-induced calcium influx in PC12 cells: possible involvement of protein kinase C. Life Sci 72:2533-2542.

Quirarte GL, Roozendaal B, McGaugh JL (1997) Glucocorticoid enhancement of memory storage involves noradrenergic activation in the basolateral amygdale. Proc Natl Acad Sci USA 94:14048-14053.
Raghavendra V, Rutkowski MD, Deleo JA (2002) The role of spinal neuroimmune activation in morphine tolerance/hyperalgesia in neuropathic and sham-operated rats. J Neurosci 22:9980-9989.

Refojo D, Liberman AC, Holsboer F, Arzt E (2001) Transcription factormediated molecular mechanisms involved in the functional cross-talk between cytokines and glucocorticoids. Immunol Cell Biol 79:385-394.

Roosendaal B, Williams GL, McGaugh JL (1999) Glucocorticoid receptor activation in the rat nucleus of the solitary tract facilitates memory consolidation: involvement of the basolateral amygdale. Eur J Neurosci 11:1317-1323.

Roosendaal B, Mcreynolds JJ, McGaugh JL (2003) The basolateral amygdala interacts with the medial prefrontal cortex in regulating glucocorticoid effects on working memory impairment. J Neurosci 24:1385-1392.

Schafers M, Svensson CI, Sommer C, Sorkin LS (2003) Tumor necrosis factor-alpha induces mechanical allodynia after spinal nerve ligation by activation of p38 MAPK in primary sensory neurons. J Neurosci 23:2517-2521.

Smith GD, Seckl JR, Scheward WJ, Bennie JG, Carroll SM, Dick H, Harmar AJ (1991) Effect of adrenalectomy and dexamethasone on neuropeptide content of dorsal root ganglia in the rat. Brain Res 564:27-30.

Song C, Phillips AG, Leonard B (2003) Interleukin 1 beta enhances conditioned fear memory in rats: possible involvement of glucocorticoids. Eur J Neurosci 18:1739-1743.

St. Hilaire M, Tremblay PO, Levesque D, Barden N, Rouillard C (2003) Effects of cocaine on c-Fos and NGFI-B mRNA expression in transgenic mice underexpressing glucocorticoid receptors. Neuropsychopharmacology 28:478-489.

Sugimoto T, Bennett GJ, Kajander KC (1990) Trans-synaptic degeneration in the superficial dorsal horn after sciatic nerve injury: effects of a chronic constriction injury, transaction, and strychnine. Pain 42:205-213.

Sweitzer S, Martin D, DeLeo JA (2001) Intrathecal interleukin-1 receptor antagonist in combination of soluble tumor necrosis factor receptor exhibits an anti-allodynia action in a rat model of neuropathic pain. Neuroscience 103:529-539.

Takahashi T, Kimoto T, Tanabe N, Hattori TA, Yasumatsu N, Kawata T (2002) Corticosterone acutely prolonged $N$-methyl-D-aspartate receptor mediated $\mathrm{Ca}^{2+}$ elevation in cultured rat hippocampal neurons. J Neurochem 83:1441-1451.

Tal M, Bennett GJ (1994) Extra-territorial pain in rats with a peripheral mononeuropathy: mechano-hyperalgesia and mechano-allodynia in the territory of an uninjured nerve. Pain 57:275-382.

Tronche F, Kellendonk C, Kretz O, Gass P, Anlag K, Orban PC, Bock R, Klein $\mathrm{R}$, Shutz G (1999) Disruption of the glucocorticoid receptor gene in the nervous system results in reduced anxiety. Nat Genet 23:99-103.

Vallee M, Mayo W, Koob GF, Le Moal M (2001) Neurosteroids in learning and memory. Int Rev Neurobiol 46:273-320.

Wall PD, Waxman SG, Basbaum AI (1974) Ongoing activity in peripheral nerve: injury discharge. Exp Neurol 45:576-589.

Watkins LR, Maier SF (2003) Glia: a novel drug discovery target for clinical pain. Nat Rev Drug Dis 2:973-985.

Woolf CJ, Mannion RJ (1999) Neuropathic pain: aetiology, symptoms, mechanisms, and management. Lancet 353:1959-1964.

Yaksh TL, Rudy TA (1976) Chronic catheterization of the spinal subarachnoid space. Physiol Behav 17:1031-1036.

Yamamoto T, Yaksh TL (1992) Spinal pharmacology of thermal hyperalgesia induced by constriction injury of sciatic nerve. Excitatory amino acid antagonists. Pain 49:121-128.

Yan P, Xu J, Li Q, Chen S, Kim GM, Hsu CY, Xu XM (1999) Glucocorticoid receptor expression in the spinal cord after traumatic injury in adults rats. J Neurosci 19:9355-9363. 